\title{
Coordinating Digital Content Generation
}

\author{
Frida Ivarsson \\ Gothenburg University \\ Swedish Center for Digital Innovation \\ frida.ivarsson@ait.gu.se
}

\author{
Lisen Selander \\ Gothenburg University \\ Swedish Center for Digital Innovation \\ lisen.selander@ait.gu.se
}

\begin{abstract}
Digital content generation has become vital for growing, diversifying, and evolving digital platforms. We note that digital content generation and its associated coordination challenges are underexplored perspectives in the digital platform literature. In this paper, we explore how members of an incumbent organization generate digital content on a shared Instagram account along with the marketing unit's emerging coordination efforts. We contribute to the digital platform literature by directing attention to the resourcing needed for the coordination of distributed digital content generators, and by demonstrating the dynamic nature of coordination mechanisms for digital content generation.
\end{abstract}

\section{Introduction}

Digital content generation has become integral to living and organizing in the age of digital platforms [3]. In 2019, the world's most downloaded apps were all highly content generative (i.e., WhatsApp, TikTok, Messenger, Facebook, Instagram $)^{1}$. According to extant literature, digital content generation implies that platform owners open up the digital platform architecture for large-scale, heterogeneous, uncoordinated actors to generate complementary digital entities in the form of digital text, image, sound, and video $[37,21,10]$. Such user-generated content can be regarded as complements - and external actors as complement generators - to the digital platform and its users. Once generated and distributed, digital content can unleash further creative potential by being recombined into new variations (e.g., GIFs, memes, and mashup songs). This phenomenon is often explained by the generative property of digital technology [21, 39].

Generativity, however, makes digital platform dynamics inherently unpredictive. Digital platform owners struggle with enabling/constraining generativity to avoid harmful complements without obliterating the potential for innovation $[38,21]$, as illustrated by extant research on how to engage third-party application developers without fragmenting the platform $[11,8,13$, $27,29]$. Such struggles can be understood as large-scale coordination of complement generators and their diverse interests and motives [10]. Surprisingly few studies have explored the distinct coordination challenges associated with digital content generation, although scholarly interest in digital content generation is growing $[1,22,2,16]$. While there are hierarchical interdependencies between different architectural layers of digital platforms (i.e., device, network, application, and content) $[14,37]$, a holistic understanding of digital platforms requires distinct consideration within and across all layers [14], including the content layer.

In this paper, we ask the following: How is digital content generation on digital platforms coordinated? Our study departs from the complement generators' perspective. We empirically explore the coordination of digital content generation through a case study of an incumbent organization, Sydved AB. In this firm, the marketing unit has distributed access to a shared Instagram account to a number of employees (i.e., distributed digital content generators), who generate digital content for branding purposes. Thereby, coordination of the employees' engagement is not only shaped by the generative conditions set by the digital platform owner, Instagram, but also the marketing unit's efforts to align the digital content generators' output with Sydved's brand identity. We identify emergent coordination mechanisms for digital content generation and trace how they dynamically unfolded over time. We conclude by theorizing on the coordination of digital content generation, shaped by the interdependency between the generative digital platform and the incumbent organization's coordination of the digital content generators.

\footnotetext{
${ }^{1}$ Visual Capitalist (2020)
} 


\section{Digital content generation}

Digital content refers to entities of digital data [14], typically represented in the form of image, video, audio, and text. In contrast to analog data, which are tightly coupled with media with distinct purposes (e.g., text in books), digital data are loosely coupled with particular devices or platforms, as they can carry any kind of content represented in binary digits. Digitization of data along with performance and price improvements of devices have resulted in widespread opportunities for essentially anyone to generate digital content [37].

Two forms of digital content generation can be distinguished. In original content generation, digital content is generated de novo, for example, by recording digital video with a digital device. In recombinational content generation, actors recombine several entities of digital content, materializing into hypothetically unlimited variations [36, 14]. Recombinational content generation is facilitated by the editability of digital content [17], becoming all the more sophisticated as the functionality of the underlying architecture becomes more advanced (e.g., "deep fake" videos), and the ease of reproducing digital content at essentially zero marginal cost [26] (e.g., downloading or screenshotting existing content). For example, in generating GIFs and memes [20], recombining multiple entities of digital content can result in endless adaptations [15]. Tracing the number of variations of memes available on the Internet, which stem from one original image, becomes seemingly impossible.

\section{Coordination and digital platforms}

In this paper, we understand digital content generation from a digital platform perspective. In extant research, digital content generation has been more rigorously addressed from a social media perspective $[28,32]$ that particularly emphasizes its affordances for social networking. In contrast, a digital platform perspective allows for understanding user-generated content as platform complements [2] - that is, externally generated resources-for fueling growth [24], diversity [7], and a continuously evolving digital platform architecture [36]. In the digital platform literature, there is a growing research interest in understanding "how governance and incentive structures can be best implemented to coordinate behavior across multiple platform stakeholders and their distinct interests" [10]. Coordination refers to a "temporally unfolding and contextualized process of input regulation and interaction articulation to realize a collective performance" [12]. Such processes are assisted by coordination mechanisms, referring to "the organizational arrangements that allow individuals to realize a collective performance," where traditional examples include plans, rules, roles, and routines [23]. However, the coordination literature reflects a move from focusing on focal rules and convergent expectations toward a focus on emergence and ongoing negotiations of cultural and political practices $[18,4$, 25]. The main argument here is that coordination processes, and cross-boundary coordination in particular, unfold through combinations of inputs and interactions among different organizational actors.

In digital platform contexts, the distribution of agency associated with generativity shapes emergent pathways through a dynamic "strategic interplay" between digital platform owners and complement generators $[10,31]$. Hence, coordination takes inherently different forms in the context of digital platforms in comparison with traditional hierarchical organizational contexts [19]. Generativity has been described as the capacity exhibited by digital technologies to "produce unanticipated change through unfiltered contributions" [38] by "large, varied, unrelated, unaccredited and uncoordinated entities/actors" [21]. However, extant research suggests that digital platform owners can at least partly coordinate complement generators [31] by "shap[ing] the extent of generativity allowed" [21]. Here, digital platform owners must delicately balance between control and autonomy of complement generators [30, 34]. The research stream focusing on the role of boundary resources $[11,13]$ in engaging and influencing the behavior of independent application developers forms a basis for understanding coordination mechanisms in digital platform contexts, identifying several technological (e.g., APIs and SDKs) and social mechanisms (e.g., regulations, rules, guidelines, extrinsic and intrinsic incentives, and intellectual property rights) $[13,37,6]$.

Scarcely explored in the literature is how coordination is accomplished for digital content generation. However, empirical research on the digital encyclopedia Wikipedia represents an exception. As the number of complement generators on Wikipedia grew, coordination mechanisms emerged from the initial principle to "ignore all rules", to a basic set of technological mechanisms to enable/constrain digital content generators (e.g., a writing tool for text generation and a reverting tool for undoing mistakes or rejecting undesired contributions) into even more complex policies (e.g., three-revert rule to avoid "edit wars" in situations of conflict) [1]. We still know relatively little about the coordination of digital content generation from the complementors' perspective and, in particular, how such processes play out within the boundaries of an incumbent organization. 


\section{Research method}

\subsection{Data collection and analysis}

We approached our research question through an indepth case study of digital content generation at Sydved AB (Sydved) [35], an incumbent organization operating in the Swedish forest industry. We conducted the study between March 2018 and April 2020. Following the marketing unit's decision to distribute digital content generation among a select few employees ("web editors"), we witnessed the marketing unit's efforts to coordinate the web editors' engagement in generating digital content in Sydved's growing social media spaces. Over time, the emphasis on generating digital content on Instagram grew, which is why we chose to focus on this particular digital platform in our study. We deeply engaged in the case setting to trace events, actions, and decisions of different stakeholders, why we collected data from multiple sources. Our data corpus includes recordings from meeting participation (1-2 per half year), document analysis, interviews, e-mails, and digital content (see overview in Table 1). The respondents include the $\mathrm{CMO}$, marketing coordinator, digital marketer, five web editors (one of them was interviewed twice), and one system developer. We had full access to internal documents, such as strategy documents and PowerPoint slides from meetings. Further, we downloaded the digital content on Sydved's Instagram account (i.e. trace data) [5].

\begin{tabular}{|l|l|c|}
\hline Data Source & Comment & Sum \\
\hline $\begin{array}{l}\text { Everyday } \\
\text { Participation }\end{array}$ & $\begin{array}{l}\text { Counted in field notes } \\
\text { containing relevant data }\end{array}$ & 6 \\
\hline $\begin{array}{l}\text { Meeting } \\
\text { Participation }\end{array}$ & $\begin{array}{l}\text { Web editor and marketing } \\
\text { unit meetings }\end{array}$ & 11 \\
\hline Interviews & $\begin{array}{l}\text { Semi-structured or } \\
\text { unstructured; one group } \\
\text { interview }\end{array}$ & 18 \\
\hline E-mails & $\begin{array}{l}\text { From marketing unit to web } \\
\text { editors, from web editor to } \\
\text { marketing unit, from } \\
\text { management to marketing } \\
\text { unit, and complementary } \\
\text { interview questions }\end{array}$ & 33 \\
\hline Documents & $\begin{array}{l}\text { E.g., web editor meeting } \\
\text { PowerPoint slides, meeting } \\
\text { notes, strategy documents, } \\
\text { social media guidelines, and } \\
\text { recruitment documents }\end{array}$ & 35 \\
\hline Trace Data & $\begin{array}{l}\text { Data from Sydved's Instagram } \\
\text { account 2017-03 - 2020-04 (e.g., } \\
\text { images, videos, captions) }\end{array}$ \\
\hline
\end{tabular}

Table 1. Overview of data set (2020-04-27).
We started the data analysis with open coding [9] using ATLAS.ti coding software. We were initially interested in exploring the cultural and political dimensions of digital content that we observed and its implications for the organization, such as tensions about digital content reflecting hunting practices. We realized, however, that such questions were related to broader questions on coordination challenges and the generativity afforded by the particular digital platform. Turning to the literature on digital platforms, we realized that there was a gap in the literature on these issues and that previous literature had particularly focused on application development. To complement this, we turned to the management literature on coordination.

With this conceptual framing in mind, we performed a second round of coding, resulting in 382 codes in total. The codes were grouped into themes in a network view in ATLAS.ti, including, for example "coordination," "organizational arrangements," "generating digital content," "content strategy," and "internal tensions." We established code links to identify relations (e.g., "rule - no engagement in politically sensitive issues" is caused by "transparency") and contradictions (e.g., "image creation" vs. "transparency") between codes. In the final round of our analysis, conducted iteratively with writing, we focused on identifying coordination mechanisms and how they emerged over time. We identified differences associated with the shift from exclusive engagement in original content generation to complementary engagement in recombinational content generation. This distinction served to structure the case narrative and theorize on the temporal dynamics of coordination mechanisms in the discussion section.

\subsection{Case background}

Sydved is an incumbent organization founded in 1979 in the Swedish forest industry. Sydved's mission is to purchase wood from forest owners and resell it to mills. Sydved has about 140 employees of whom approximately $50 \%$ are "forest buyers" responsible for wood purchases. This paper pays particular attention to these forest buyers and the marketing unit. In 2019, there were seven geographically dispersed forest buyer districts organized according to the principle of geographical decentralization to cover local markets in southern parts of rural Sweden. The marketing unit, situated remotely from the forest buyers at the central office, consists of the $\mathrm{CMO}$, marketing coordinator, marketing support, digital marketer (employed June 2018), and one system developer (shared resource with the IT unit). To support forest buyers, a key component of the marketing unit's established branding efforts is the quarterly magazine Active Forestry-in other 
words, printed content. Here, the marketing coordinator mainly generates articles herself and coordinates complementary content generated by local writers and photographers.

In 2013, Sydved's CMO initiated an organizational reconfiguration, the "Sydved Online Team", for generating digital content across multiple platforms for branding purposes. This team includes members from the marketing and IT units and one forest buyer from each geographical district ("web editors"). In contrast to wood purchasing, this engagement is voluntary and unpaid. In March 2017, Sydved's marketing coordinator registered an Instagram account. At the time, the user base of Instagram consisted of 800 million users ${ }^{2}$, making it an appealing platform for Sydved's marketing unit to attract forest owners at scale (CMO PowerPoint slides, 2013-11-29). Instagram is a digital platform owned by Facebook Inc. since 2012, containing multiple, distinct technological features for digital content generation (e.g., Instagram stories, Instagram $\mathrm{TV})^{3}$. The web editors at Sydved mainly generate Instagram feed posts - namely, images and/or videos with related short texts ("captions"). The decision to open Sydved's Instagram account led to unfamiliar challenges for Sydved's marketing unit in coordinating the web editors' efforts.

\section{The Sydved case}

[The] purpose with Sydved on Instagram [is to]: highlight the positive aspects of the forest owner lifestyle; expose a professional, serviceminded, responsible and sustainable firm that advocates "active forestry," and create trust and a sense of affinity with Sydved so our existing suppliers continue their collaboration with us and other forest owners choose to collaborate with us. (Instagram strategy, 2017-11)

\subsection{Coordinating original content generation}

In September 2017, Sydved's marketing unit decided to introduce Instagram to a number of forest buyers, the web editors. These web editors were asked to frequently generate content on Sydved's Instagram account and were already equipped with necessary devices to do so (e.g., mobile phones with a camera application). While the marketing unit previously had been in control of the Instagram account, they sensed that they were failing to reach forest owners. "Before, it was only us [the marketing unit] who generated content.
It was mostly 'lifestyle' posts, such as food recipes and beautiful images. [...] As we did not manage to attract the right target group, we do less of that now. [...] [By analyzing the effects of this content strategy on the website, we found out that] many who read about food recipes [left the page afterwards]" (Marketing assistant interview, 2019-09-26).

The newly engaged web editors perceived Instagram as easy to use and accessible [39]: "It's so simple. You have your phone in your pocket, you take an image, and you write some funny sentences and then you post" (Forest buyer 1 interview, 2019-11-08). Consequently, digital content generation became viewed less as an "extra" work task and became part of the web editors" everyday tasks: "These are images you take when out in the field working. It's not so that I take the phone one day and decide that "today I will take a picture for Instagram" [...] Suddenly, you see something and you need to be ready to snap an image" (Forest buyer 2 interview, 2019-11-18).

For the marketing coordinator, however, the spontaneity of web editors generating Instagram content became associated with less control than she had asserted before. With Instagram, she faced challenges in editing original content distributed on Instagram by web editors. Basically, the Instagram application constrains users from editing images or videos in Instagram feed posts retrospectively; such editing is only enabled for text-based "captions." To integrate understandings of what kind of digital content aligned with the marketing unit's desired portrayal of the Sydved brand, the marketing coordinator developed Instagram content guidelines for the web editors on what to include in images and videos. "[In terms of] what kinds of posts/photos/videos [are expected to be generated, that includes], for example, [images of] forests, nature, forestry, machines, machine operators, Sydved employees in the forest, recreation, mushrooms/berries in the forest [and, news] from your local forest events" (Instagram strategy, 2017-11).

These initial guidelines were open-ended and still granted the web editors a high degree of autonomy in what content to generate. Consequently, the web editors generated original content that largely mirrored their conceptions of the forest buyer profession, especially their widely shared interest in forests, forestry, and forestry machines. "As I like machines a lot myself, I feel that it is something that attracts readers a lot, too" (Forest buyer 3 interview, 2019-11-15). Another web editor explained, "I try to think a lot about what I would want to read myself [...]. So, it might be very selfcentered" (Forest buyer 4 interview, 2019-02-20).

\footnotetext{
${ }^{2}$ Statista (n.d.)
}

${ }^{3}$ Timeline of Instagram, Wikipedia (n.d.) 
The generated content not only mirrored their own professional interests but also their personal lives and preferences. One web editor generated an image of his dog with the initial purpose of sharing it with his wife: "At first, I took the image with the intention to send it to my wife and say 'look how nice our dog is' or something. And then I sat there and thought, 'what the hell, maybe I should post that on [Sydved's] Instagram account" (Forest buyer 1 interview, 2019-11-08). Another web editor even shared an image of his son: "The other day, I even posted an image of my sevenmonth-old son who was about to sign a contract [laughter]. [...] A lot of people thought that was a funny idea, as he sat there looking a bit serious with a pen and a contract in his hands" (Forest buyer 3 interview, 2019-11-15).

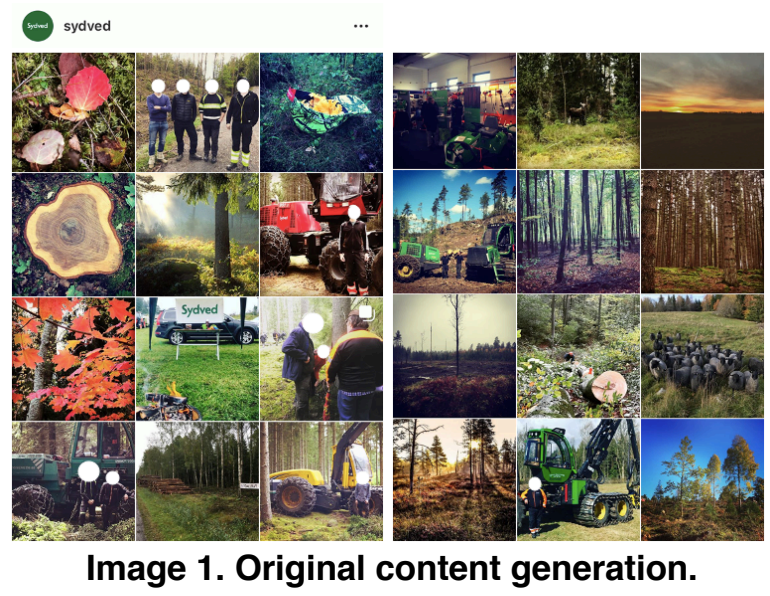

The web editors' digital content, hence, spanned the boundaries of the organization, becoming personal. This became problematic for the marketing unit, realizing that the Instagram platform introduced challenges of transparency [32] as well as potential cultural and political difficulties. For branding purposes, the marketing unit deemed that digital content needed to reflect the identity and shared language of Sydved, not unfiltered personal preferences. The marketing unit was particularly worried about "politicization" and that the content would trigger environmental movements to engage in reproducing Sydved-generated posts for their political purposes, potentially harming the Sydved brand. For example, most forest buyers had a personal interest in hunting, which was identified as a particularly sensitive political topic. Responding to this worry, the $\mathrm{CMO}$ tried to foresee such situations and communicated a principle: Sydved should not generate digital content that implies taking a stance in any politically sensitive debate, including hunting, to avoid unprompted external reactions: "In hunting seasons, we have told [the web editors who are also] hunters to be aware of that images where they pose with a dead moose or something can infuriate people very, very much. We need to avoid that" (Marketing assistant interview, 2019-09-26).

Internally, this filtering of original digital content triggered tensions amongst some forest buyers/web editors. The marketing unit responded by inviting them to discuss the sensitive issue collectively. One web editor explained as follows: "One web editor filmed when an elkhound was arranging elks. [...] And that brings us to back to [the principle proclaimed by the CMO] that we shall not take a stance in any debates. [...] I remember that we discussed that [between the marketing unit and web editors]: 'yes, many of us are [hunters], but perhaps many of our followers don't appreciate to see pictures of that.' Thank God that a picture of a dead animal never was posted" (Forest buyer 1 interview, 2019-11-08).

In 2018, a digital marketer was recruited to the marketing unit. Educated in graphic design and digital marketing, she started analyzing how the web editors' Instagram posts were performing in terms of diversity (age, sex, and geographical location of reached actors), scale (e.g., number of followers/reached actors of posts, timing of posts generating the most interactions), and user engagement (e.g., number of likes/comments). This resulted in a new set of guidelines for digital content generation on Instagram, such as frequency and timing of generating digital content. Further, she identified that video-based Instagram posts performed better in terms of reach: "I try to encourage [the web editors] to generate videos. [...] The [Instagram] algorithm likes [i.e., prioritizes video over images in the feed] right now" (Digital marketer interview, 2018-12-18).

Following some violations of these new guidelines, the marketing unit introduced sanctions. An example of such sanctions was the removal of Instagram posts. As web editors distributed generated posts instantly, and Instagram constrains users from time delaying posts, "inappropriate" digital content needed to be removed retrospectively. For the marketing unit, the need to be responsive made coordination more resource intensive. "We [i.e., the marketing unit] should always keep an eye on Instagram. [...] We have been in contact several times during the weekends to check if we have received a comment or something that needs to be answered" (Digital marketer interview, 2019-12-19). For example, one post was deleted because the image portrayed alcohol consumption, which was worrying for potential responses amongst external actors. "[The digital marketer] removed something I posted [laughter]. [...] Schnapps made from fir cones wasn't something she was very fond of. I thought it was a nice moment [...] but I had no problem with [that she removed the picture]" (Forest buyer 1 interview, 2019-11-08). As Instagram constrained the digital marketer from identifying the individual web editor who had generated 
the post, she needed to e-mail all the web editors: " $\mathrm{Hi}$ everyone! This Friday I deleted one of your Instagram posts (I don't know whose). [...] We try to avoid alcohol in images, as alcohol is not something we want associated with the Sydved brand. It can easily be wrongly interpreted in the eyes of others. [...] Otherwise, great activity on Instagram [...], just think about what you publish" (Digital marketer e-mail, 2018-10-05).

Unlike most Sydved employees, the digital marketer neither had a background nor prior interest in forestry. She was critical to the homogeneous content generated by the web editors and the homogeneous set of external actors it attracted. The digital marketer noted that only $17 \%$ of the firm's Instagram followers were women, although $38 \%$ of forest owners were women ${ }^{4}$ and Instagram was used more by women than men in Sweden ${ }^{5}$. Thereafter, "diversifying the target audience" was inscribed as a goal in the marketing strategy (Digital marketer PowerPoint slides, 2018-11-15). She reasoned that diversifying the values reflected in the content would result in diversity amongst their followers. "We think that we need to work more with other values. Right now, the forest buyers are posting a lot of [content] on forestry machines. We think that we should work more with 'sustainability' and 'the future,' because we think that can attract... well maybe not primarily women, but a more diverse set of actors" (Digital marketer interview, 2018-11-14). Further, not all forest owners in Sweden share the interests of Sydved's forest buyers: "Not every [forest owner] lives this [conventional] forest owner life. One might perhaps live in the city... But how should [we] portray that on Instagram?" (Digital marketer interview, 2019-08-15).

In the pursuit of more diversified content, the marketing unit struggled with identifying complementary coordination mechanisms. They did not want to jeopardize the web editors' engagement that was built on autonomy and intrinsic motivation. As illustrated by one web editor: "I want to do something different than the mundane work tasks [and share] my knowledge in writing that I otherwise wouldn't get the opportunity to do. [Further], it is kind of a fun challenge [to engage in new work tasks]" (Forest buyer 4 e-mail, 2020-04-10). The web editors' efforts had indeed resulted in scaling of followers, reaching 1,667 in September 2019, aligned with the purpose of Instagram in the marketing strategy: "We want diversity in our Instagram content. [...] At the same time, our core business is related to forestry [and] we can see that pictures of harvesters, forwarders and trucks receives more likes and greater reach in general" (Digital marketer email, 2019-09-23).

\subsection{Coordinating recombinational content generation}

In 2019, the digital marketer began engaging in recombinational content generation, to complement the web editors' original content. This initiative made content generation more resource intensive, requiring extra time and competence (e.g., digital video editing). Here, new devices for generating video were used (i.e., drones) in combination with video generated with phones. As the features for recombinational content generation enabled by Instagram were limited to Instagram Stories (e.g., enabling users to blend GIFs and Spotify songs with images/videos), the digital marketer needed to rely on additional software before distributing Instagram posts in the feed. To include music, the digital marketer reproduced audio from open digital platforms. "I edit all films in [Adobe] Premier Pro, some content in animation programs called [Adobe] After Effects and [Adobe] Illustrator. We have downloaded several [audio] jingles that we have used from BenSound" (Digital marketer email, 2020-02-03).

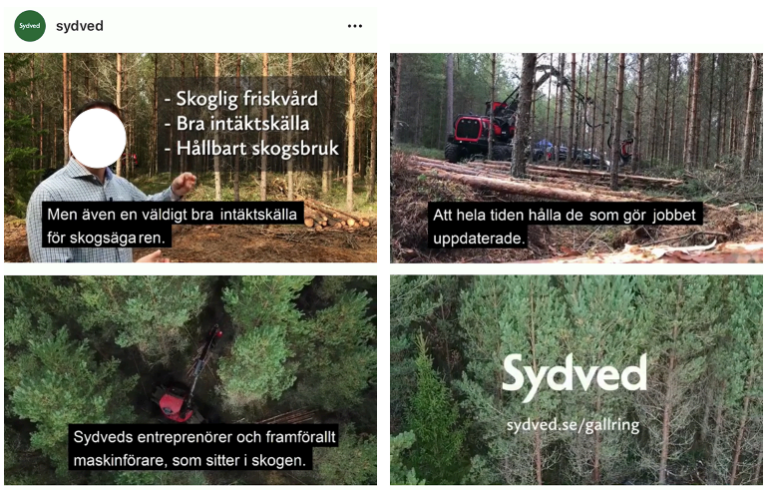

Image 2. Recombinational content generation.

By the end of summer 2019, the marketing unit was planning to generate digital content for an Advent calendar. Here, they sought to engage employees across all organizational units in generating digital video. For example, the $\mathrm{CEO}$ was asked to generate a video for Christmas Eve from his home, in which he would be dressed up as Santa Claus. These videos would then be recombined with additional digital entities by the digital marketer (e.g., an intro with a Christmas jingle, the Sydved logotype, and "Merry Christmas" in text). In this sense, coordination of the Advent calendar came to include the digital marketer's content generation efforts as well. Further, expectations and resourcing needed for generating digital video content were raised, as employees were expected to act in teams in front of the 
camera and bring props to include in the videos (e.g., cultural artifacts associated with Christmas).

Coordinating the Advent calendar constituted a move toward more formal coordination mechanisms. To make multiple digital entities recombinable in an esthetic manner, the digital marketer introduced rules for video formatting (time limitations and horizontal orientation). Further, no other Instagram posts were allowed during the first 24 days in December. As the recombinational content generation was dependent upon the digital marketer's expert competence in graphic design, she introduced plans for when to submit content to her and for when to post specific content (e.g., digital content for Lucia Day needed to be posted on December 13). "[The posts] should consist of a short video of 15-30 seconds [that feels] personal and preferably has a Christmas feeling. You will send the videos to me beforehand so we will have the chance to add an intro. [The videos should] have one or several people in focus. Record [people] close-up, i.e., from the waist and up, so the audio recording has as good quality as possible. Record horizontally" (Digital marketer email, 2019-10-15). Given the increased expectations, the marketing unit introduced minor extrinsic incentives for the best performing posts (i.e., gift card $\approx 50$ USD and cake for the winning districts), measured in likes.

Generating video according to the new rules proved difficult for some employees. The digital marketer tried to encourage an inexperienced group of employees to make several attempts. "[One video] was four minutes long, and it's not possible to post a video longer than one minute if you stick to [Instagram posts], and we had decided not to generate content for Instagram $T V$. We don't want to kill their engagement, but it was too difficult to cut its length. I mean, they brought a stuffed hare to work to include in the video [and engaged] although they were uncomfortable with it at first. So, it was tough [to refuse the video]. And then we received a second video [sigh] and it was recorded in vertical format..." (Digital marketer interview, 2019-12-19). After a second request for a new video, the forest buyers decided not to reply and resisted by not generating a third video. In some ways, the tight control of the marketing unit had lowered the intrinsic motivation for content generation.

As the marketing unit deliberately sought a high degree of transparency of local cultural practices associated with Christmas in the Advent calendar, a new coordination mechanism was implemented to avoid potential unprompted responses from external actors. This time, all videos needed to be approved by the $\mathrm{CMO}$ before distribution. As the videos were shared with the digital marketer through additional content-sharing software instead of being distributed directly on Instagram, this prospective form of sanctioning was possible. One video was considered to violate the management team's view on safety at work, as one forest buyer was driving a car without a seatbelt. The digital marketer solved this by editing the video in Adobe before distribution. Although half the video was posted, the forest buyers were disappointed because she had downplayed a humorous element that they were proud of-where "Santa" was shown written on the license plate.

Despite the attempts at formal control, the marketing unit faced a situation where they needed to revise and align their coordination efforts. One forest buyer generated a video expressing that "We have a slightly different way of cutting down Christmas trees. We shoot them down instead of using an axe" (Forest buyer 2 interview, 2019-11-18). Given its authentic portrayal of the local culture, the video was approved initially, despite conflicting with the management team's value of safety in the workplace. The forest buyer was not using safety spectacles. In response to a user-generated comment reacting to this, the $\mathrm{CMO}$ reconsidered his decision: "[The CMO] called me and said: 'you need to remove when he shoots!' [...] Of course, it is good to be 'politically correct', but perhaps it would have [made us look] better [in the eyes of external actors and Sydved employees] if we had responded with an explanation of why [the forest buyer did not use spectacles this one time]" (Digital marketer interview, 2019-12-19). Although it was Saturday and she had other plans, the digital marketer spent approximately an hour recombining the video by adding a black image with a firework animation to substitute for the shooting before reposting the video.

\begin{tabular}{|l|c|c|}
\hline \multirow{2}{*}{$\begin{array}{c}\text { Coordination } \\
\text { Mechanism }\end{array}$} & \multicolumn{2}{|c|}{ Primary Association } \\
\cline { 2 - 3 } & $\begin{array}{l}\text { Coordinating } \\
\text { Original } \\
\text { Content } \\
\text { Generation }\end{array}$ & $\begin{array}{l}\text { Coordinating } \\
\text { Recombinational } \\
\text { Content } \\
\text { Generation }\end{array}$ \\
\hline Guidelines & $\mathrm{X}$ & \\
\hline Principles & $\mathrm{X}$ & $\mathrm{X}$ \\
\hline Sanctions & Retrospective & Prospective \\
\hline Rules & & $\mathrm{X}$ \\
\hline Plans & & $\mathrm{X}$ \\
\hline $\begin{array}{l}\text { Intrinsic } \\
\text { Incentives }\end{array}$ & & \\
\hline $\begin{array}{l}\text { Extrinsic } \\
\text { Incentives }\end{array}$ & & \\
\hline
\end{tabular}

Table 2. Coordination mechanisms for digital content generation in the Sydved case. 


\section{Discussion}

Our ambition with this paper is to improve the understanding of digital content generation on digital platforms and its associated coordination challenges. These challenges, we claim, are related to the generativity of the digital technology, the interdependencies between the contextual conditions of digital content generators and the digital platform, and the heavy resourcing needed to establish explicit and tacit coordination mechanisms. While extant research has formed a basis for understanding coordination in digital platform contexts, typically investigating thirdparty application developers $[13,33,37,6,11]$, there is scant research on complement generators devoted to digital content generation and the particular coordination challenges associated with the content layer of digital platforms. Our empirical inquiry into Sydved's coordination efforts of distributed digital content generators makes the following contributions to the digital platform literature.

First, our empirical study on Sydved directs attention to the emergent and resource-intensive contextual coordination efforts associated with complementors' generation of digital content on digital platforms. While the digital platform owner sets conditions for enabling/constraining digital platform generativity [21], such coordination efforts are essentially contextagnostic. In response, processes of contextual coordination of digital content generation rest with complementors. Most notably, our study on Sydved highlights that contextual coordination of digital content generation is highly characterized by ongoing negotiations in cultural and political struggles $[18,4]$ spanning organizational professions, units, and boundaries. The most salient example concerned digital content portraying hunting practices, which was considered highly politically sensitive. Eventually, the CMO established a principle that digital content should not reflect any politically sensitive topic. This principle, however, was not without controversy. As some forest buyers/web editors identified as hunters, this resulted in issues of identity [18]. Here, the marketing unit faced the challenge of revising and aligning its conceptions of Sydved's brand identity with organizational members' conceptions of their professional, and even personal, identity. In an attempt to resolve emerging disagreements, the marketing unit responded by initiating collective discussions with the web editors to pursue a shared understanding [4].

Second, the Sydved case illustrates a number of specific coordination mechanisms that assist in coordinating distributed digital content generators (see overview in Table 2) and their dynamic nature. To understand the emergence and dynamics of these coordination mechanisms, however, it is essential to recognize both the complementors' coordination efforts (in this case, an incumbent organization) and the generative conditions of the digital platform Instagram.

From the organizational perspective, Sydved's marketing unit's increasing ambitions for using Instagram for branding purposes and the established hierarchical structure of the firm shaped how the coordination mechanisms unfolded. We observed Sydved's marketing unit gradually exploring a diverse flora of coordination mechanisms intended for the web editors, which resembled some of the mechanisms identified in the literature for coordinating third-party application developers [13, 6, 11], such as guidelines (i.e., for what to portray in images/videos), principles (e.g., no digital content generation of politically sensitive issues), and sanctions (e.g., removing posts violating guidelines/principles). Over time, we noted significant differences in Sydved's marketing unit's initial efforts to coordinate original content generation and later efforts to coordinate recombinational content generation. This temporal distinction illustrates how different sets of coordination mechanisms assist in balancing and revising the degree of autonomy/control of digital content generators over time [30, 34]. Initially, the efforts for coordinating web editors' original content generation were associated with a high degree of autonomy, reflected in the fairly open-ended guidelines on what to portray in digital content. The high degree of autonomy was a challenge for the marketing unit to balance. There was increasing reliance on the established hierarchical structure for implementing value-laden principles, such as the CMO's declaration of the principle of not generating digital content on hunting. Over time, tighter coordination mechanisms were introduced, such as rules (e.g., orientation and length of videos) and plans (e.g., when to generate content). This triggered some signs of resistance and disengagement amongst digital content generators. For example, some lost their motivation when expectations for the Advent calendar increased. This observation indicates that formal control attempts over digital content generation may come at the expense of resistance and loss of engagement.

From the digital platform perspective, the emergence of these coordination mechanisms cannot be understood in isolation from how the underlying architectural design of the digital platform enables/constrains generativity $[21,14]$. We noted several instances where the marketing unit found itself constrained that illustrate this point. For example, the guidelines for what to portray in images/videos emerged as the marketing unit was constrained from editing images and videos in Instagram posts retrospectively. Further, the principle of avoiding politically sensitive content emerged as a 
precaution, as Instagram posts generated by web editors were distributed instantly, and sanctioning was, therefore, only possible retrospectively. Yet we noted that the marketing unit was able to work around the constraints of the Instagram application in recombinational content generation by relying on other applications (i.e., digital image/video sharing and editing software) before distributing content on Instagram. The loose coupling of digital content and underlying architectural conditions lessened the dependency on the Instagram application [37] for the marketing unit to pursue its vision with the Advent calendar. This allowed for sanctioning content prospectively (i.e., approving posts before distribution). This observation indicates that the coordination of digital content generation is particularly challenging because of the loose coupling of digital content and platforms/devices, especially in comparison with coordinating complements on other architectural layers.

We believe the coordination of digital content generation represents fertile ground for future research. Based on the Sydved case, we propose coordination challenges related to diversification in digital content generation as one potential avenue. In the Sydved case, we found that the marketing unit faced challenges in diversifying both the digital content itself and the set of actors it attracted, such as the gender imbalance amongst followers. For the marketing unit, the barriers of resourcing and risks of jeopardizing the web editors' engagement were perceived as too high for exploring coordination mechanisms for diversity; hence, the web editors were encouraged to continue openly sharing digital content pertaining to their personal interests, despite its inherent homogeneity. Based on this observation, subsequent studies could address how to coordinate digital content generation for diversity, how to shape the generativity of digital platforms to foster diversity, or examine the organizational and social consequences of failing to design digital platforms that foster diversity.

Future studies could also address the following limitations of our study. First, while we generated a rich set of data by focusing on the coordination of digital content generation on a considerably small scale (i.e., one Instagram account), future studies could address coordination challenges from the digital platform owner's perspective, involving coordination of stakeholders with diverse interests and motives on larger scales. Second, while we observed no significant architectural changes in the Instagram application during the study, future studies could address implications for coordinating digital content generation as the underlying digital platform architecture evolves. Finally, while the empirical context of our study generated insight into context-specific contextual struggles, future studies could explore how other contextual conditions shape the coordination of digital content generation, such as in the public sector, NGOs, and firms, in other industries/politico-cultural contexts.

\section{References}

[1] A. Aaltonen and G. F. Lanzara, "Building governance capability in online social production: Insights from Wikipedia", Organization Studies, 36 (2015), pp. 1649-1673.

[2] C. Alaimo, J. Kallinikos and E. Valderrama, "Platforms as service ecosystems: Lessons from social media", Journal of Information Technology, 35 (2020), pp. 25-48.

[3] R. Baskerville, M. Myers and Y. Yoo, "Digital first: The ontological reversal and new challenges for IS", MIS Quarterly (2019).

[4] B. A. Bechky, "Sharing meaning across occupational communities: The transformation of understanding on a production floor", Organization Science, 14 (2003), pp. 312330.

[5] N. Berente, S. Seidel and H. Safadi, "Research commentary - data-driven computationally intensive theory development", Information Systems Research, 30 (2019), pp. 50-64.

[6] K. Boudreau and K. Lakhani, "How to manage outside innovation", MIT Sloan Management Review, 50 (2009), pp. 69-76.

[7] K. J. Boudreau, "Let a thousand flowers bloom? An early look at large numbers of software app developers and patterns of innovation", Organization Science, 23 (2012), pp. 14091427.

[8] C. Cennamo and J. Santaló, "Generativity tension and value creation in platform ecosystems", Organization Science, 30 (2019), pp. 617-641.

[9] K. Charmaz, Constructing grounded theory: A practical guide through qualitative analysis, SAGE, 2006.

[10] P. Constantinides, O. Henfridsson and G. G. Parker, "Introduction - platforms and infrastructures in the digital age", Information Systems Research (2018), pp. 381-400.

[11] B. Eaton, S. Elaluf-Calderwood, C. Sorensen and Y. Yoo, "Distributed tuning of boundary resources: the case of Apple's iOS service system", MIS Quarterly: Management Information Systems, 39 (2015), pp. 217-243.

[12] S. Faraj and Y. Xiao, "Coordination in fast-response organizations", Management Science, 52 (2006), pp. 11551169.

[13] A. Ghazawneh and O. Henfridsson, "Balancing platform control and external contribution in third-party development: 
the boundary resources model", Information Systems Journal, 23 (2013), pp. 173-192.

[14] O. Henfridsson, J. Nandhakumar, H. Scarbrough and N. Panourgias, "Recombination in the open-ended value landscape of digital innovation", Information and Organization, 28 (2018), pp. 89-100.

[15] T. Highfield and T. Leaver, "Instagrammatics and digital methods: Studying visual social media, from selfies and GIFs to memes and emoji", Communication Research and Practice, 2 (2016), pp. 47-62.

[16] P. Hukal, O. Henfridsson, M. Shaikh and G. Parker, "Platform signaling for generating platform content", MIS Quarterly, 44 (2020), pp. 1177-1205.

[17] J. Kallinikos, A. Aaltonen and A. Marton, "The ambivalent ontology of digital artifacts", MIS Quarterly (2013), pp. 357-370.

[18] K. C. Kellogg, W. J. Orlikowski and J. Yates, "Life in the trading zone: Structuring coordination across boundaries in postbureaucratic organizations", Organization Science, 17 (2006), pp. 22-44.

[19] A. Lindberg, N. Berente, J. Gaskin and K. Lyytinen, "Coordinating interdependencies in online communities: A study of an open source software project", Information Systems Research, 27 (2016), pp. 751-772.

[20] K. M. Miltner and T. Highfield, "Never gonna GIF you up: Analyzing the cultural significance of the animated GIF", Social Media + Society, 3 (2017), pp. 1-11.

[21] S. Nambisan, M. Wright and M. Feldman, "The digital transformation of innovation and entrepreneurship: Progress, challenges and key themes", Research Policy, 48 (2019), pp. $1-9$.

[22] D. Nylén and J. Holmström, "Digital innovation in context", Information Technology \& People (2019), pp. 696714 .

[23] G. A. Okhuysen and B. A. Bechky, "Coordination in organizations: An integrative perspective", Academy of Management Annals, 3 (2009), pp. 463-502.

[24] G. G. Parker, M. W. Van Alstyne and S. P. Choudary, "Pipelines, platforms, and the new rules of strategy", Harvard Business Review, 94 (2016), pp. 54-62.

[25] P. Puranam, O. Alexy and M. Reitzig, "What's 'new' about new forms of organizing?", Academy of Management Review, 39 (2014), pp. 162-180.

[26] C. Shapiro and H. R. Varian, Information rules: A strategic guide to the network economy, Harvard Business Press, 1998.
[27] D. Skog, H. Wimelius and J. Sandberg, "Digital service platform evolution: How Spotify leveraged boundary resources to become a global leader in music streaming", Proceedings of the 51st Hawaii International Conference on System Sciences, 2018, pp. 4564-4573.

[28] A. N. Smith, E. Fischer and C. Yongjian, "How does brand-related user-generated content differ across YouTube, Facebook, and Twitter?", Journal of Interactive Marketing, 26 (2012), pp. 102-113.

[29] F. Svahn, R. Lindgren and L. Mathiassen, "Applying options thinking to shape generativity in digital innovation: An action research into connected cars", Proceedings of the 48th Hawaii International Conference on System Sciences, 2015, pp. 4141-4150.

[30] D. Tilson, K. Lyytinen and C. Sorensen, "Digital infrastructures: The missing IS research agenda. (research commentary)", Information Systems Research, 21 (2010), pp. 748-759.

[31] A. Tiwana, B. Konsynski and A. A. Bush, "Platform evolution coevolution of platform architecture, governance, and environmental dynamics", Information Systems Research, 21 (2010), pp. 675-687.

[32] J. W. Treem and P. M. Leonardi, "Social media use in organizations: Exploring the affordances of visibility, editability, persistence, and association", Annals of the International Communication Association, 36 (2013), pp. 143189.

[33] S. Um, Y. Yoo, S. Wattal, R. Kulathinal and B. Zhang, "The architecture of generativity in a digital ecosystem: A network biology perspective", Proceedings of the 34th International Conference on Information Systems, 2013.

[34] J. Wareham, P. B. Fox and J. L. Cano Giner, "Technology ecosystem governance", Organization Science, 25 (2014), pp. 1195-1215.

[35] R. K. Yin, Case study research: Design and methods, London: SAGE, 2014.

[36] Y. Yoo, "The tables have turned: How can the information systems field contribute to technology and innovation management research?", Journal of the Association for Information Systems, 14 (2012), pp. 227-236.

[37] Y. Yoo, O. Henfridsson and K. Lyytinen, "Research commentary - the new organizing logic of digital innovation: an agenda for information systems research", Information Systems Research, 21 (2010), pp. 724-735.

[38] J. Zittrain, The future of the internet-and how to stop it, Yale University Press, 2008.

[39] J. Zittrain, "The generative internet", Harvard Law Review (2006), pp. 1974-2040. 